\title{
Platón, las pasiones y la crítica al populismo Plato, passions and criticism of the populism
}

\author{
Álvaro Vallejo Campos \\ Universidad de Granada \\ avallejo@ugr.es
}

Recibido: 31/07/2019 - Aceptado: 31/01/2020

DOI https://doi.org/10.20318/fons.2019.4909

\begin{abstract}
Resumen
La tesis principal de este artículo es que la trascendencia política de las pasiones determina en Platón sus planteamientos éticos y políticos. La primera vez que se ocupa de ellas más sistemáticamente, como ocurre en el Gorgias, aparecen directamente involucradas en la crítica del imperialismo y de los procedimientos retóricos propios de la democracia ateniense, y su tratamiento debe ser uno de los ingredientes esenciales de la política concebida como un arte. Pero en la República el estado ideal surge de una reflexión sobre la necesidad de realizar una purgación de las pasiones en la ciudad lujosa y afiebrada que se trata de reformar. La importancia de la cuestión se deriva del hecho de que una teoría de la justicia en el individuo y en el estado consiste, en definitiva, en formular un ideal normativo de las relaciones que deben establecerse entre la razón y las pasiones del alma. A consecuencia de ello, las formas degeneradas del estado ideal pueden interpretarse como una secuencia en sentido creciente de la ilegítima irrupción de las pasiones en la sociedad enferma que se opone a aquel.
\end{abstract}

Palabras clave: Platón, pasiones, política, retórica, estado ideal, justicia, populismo

\begin{abstract}
The main thesis of this paper is that the political transcendence of passions determines Plato's ethical and political points of view. The first time that he deals systematically with passions, as occurs in the Gorgias, they are directly implicated in the critic of imperialism and the rhetorical procedures of Athenian democracy. They are also an essential part of politics conceived as an art. In the Republic, the ideal city emerges as the necessity of practicing a purge of passions in the luxuriant or feverish city that has to be purged. The importance of this issue derives from the fact that the theory of justice in the individual and the city consists of a normative ideal on the relations that have to be established between passions and reason. As a consequence, the sequence of the degenerated forms of the ideal state can be interpreted as an increasing model of the illegitimate irruption of passions in the ill society opposed to it.
\end{abstract}

Keywords: Plato, passions, politics, rhetoric, ideal state, justice, populism

ПНГН / F ON S 4 (2019), 55-76

ISSN 2445-2297 www.uc3m.es/pege
Á. Vallejo Campos, Platón, las pasiones y el populismo DOI https://doi.org/10.20318/fons.2019.4909 


\section{Introducción}

La concepción platónica de las pasiones se puede abordar desde muchos puntos de vista, que van desde la ética a su concepción de la racionalidad, la antropología o la teoría del alma. En esta ocasión, sin embargo, vamos a centrarnos en la trascendencia política de las pasiones. No es, desde luego, una cuestión marginal en Platón, pues le preocupaba de una manera extraordinaria y la tuvo muy en cuenta al plantear su visión de la situación histórica, tal y como él la vivió, su crítica de los regímenes políticos vigentes y sus propias alternativas éticas y políticas.

Una demostración de la importancia que tienen para Platón las pasiones en su proyección política nos la proporciona el Gorgias, que podemos considerar una obra de transición entre los llamados diálogos socráticos y el segundo grupo de madurez. No es una casualidad, en este sentido, que sea también en este diálogo donde por primera vez se manifiestan con claridad los contenidos más propios de su pensamiento, como la consideración de la política como un arte y la inmortalidad del alma. Las pasiones están ya aquí en el centro mismo de todas las consideraciones como un núcleo muy poderoso que habrá que tener en cuenta desde ahora, junto a la herencia recibida del intelectualismo socrático, también presente en el diálogo.

Desde el punto de vista de la clarificación terminológica, el concepto de epithymía, que solemos traducir por pasión, deseo o apetito, es muy amplio y no tiene por qué estar vinculado necesariamente solo a las pasiones o los deseos concupiscibles. Es verdad que Platón utiliza este término al denominar "irracional y concupiscible"

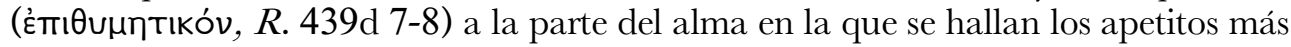
sensuales, como el hambre, la sed o el deseo sexual. En un contexto todavía no determinado por la teoría platónica, lo utiliza también Céfalo $(R .329 \mathrm{c} 7)$ en ese sentido cuando hace referencia a los apetitos sexuales que se atemperan con la vejez, procurando al hombre la "paz y la libertad" que anteriormente se veían perturbadas por estas pasiones del cuerpo. Pero, en Platón, el concepto es mucho más amplio. En la metáfora hidráulica que utiliza para describir el funcionamiento y la interrelación de las diversas fuentes motivacionales que existen en el alma ${ }^{1}$, queda claro que hay

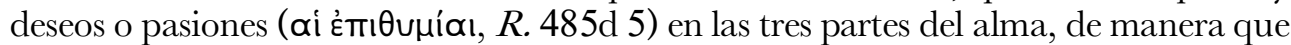
si se atenúan las pasiones que tienen como objeto los placeres corporales, se fortalece la pasión por el conocimiento y todo aquello que ha de prevalecer en la naturaleza del

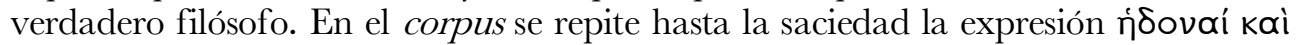
غ̇mı placeres, que son el objeto propio de la fuerza motivacional contenida en ellas. Sin embargo, no hemos de olvidar que, si existen tres partes en el alma, también hay en

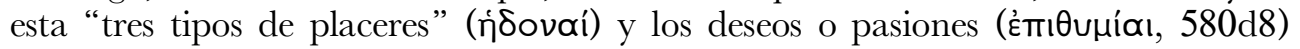
correspondientes.

\footnotetext{
${ }^{1}$ Cfr. Vallejo Campos 2018, 160 y ss.
} 
Si esto es así y Platón admite lo que para buena parte de la filosofía contemporánea sería una especie de error categorial ${ }^{2}$, al atribuir a la razón en sí misma pasiones y deseos, también es cierto que su mayor preocupación eran las pasiones irracionales derivadas de los deseos más directamente conectados con el cuerpo. Es este, dirá Sócrates en el Fedón (66c), el que nos llena de "amores y pasiones, de temores y de toda clase de aprensiones" y, en consecuencia, a su juicio, no hay que buscar en otro lado el origen de "guerras, conflictos y batallas" más que en "el cuerpo y sus pasiones"

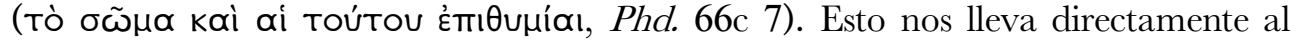
Gorgias, porque es en esta obra donde Platón mostró por primera vez su conciencia del efecto destructivo que podían tener las pasiones en el escenario de una ciudad enferma, corrompida por los enfrentamientos internos y el imperialismo desatado por los deseos irracionales que los estadistas se encargaron de alentar.

\section{El Gorgias}

Los llamados diálogos socráticos están centrados sobre todo en unas indagaciones éticas que hallan su fundamento en el intelectualismo y el esclarecimiento de los contenidos cognitivos que corresponden a las virtudes, sin que por el momento tengamos muy claro el papel que corresponde a las pasiones en el meollo de los problemas morales que en ellos se dilucidan. Sin embargo, en el Gorgias no se habla solo de la razón. Al hilo de los graves enfrentamientos políticos y de la crisis profunda que afectaba a la democracia ateniense, salta al primer plano teórico la conciencia clara de que hay "una parte del alma en la que residen las pasiones" (тоũTo tñs

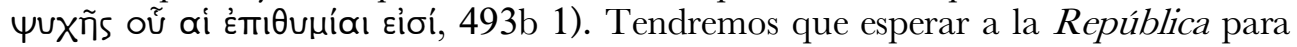
hallar la teoría en la que se inserta este elemento llamado a rebelarse contra el imperio de la inteligencia, en el que parecía cifrado hasta ahora el único factor importante de la vida moral. Pero, si nos falta todavía la teoría del alma, por muy imprecisa y deficiente que esta sea a la hora de especificar en la República el estatuto ontológico que corresponde a las partes o especies del alma, no por eso deja de resaltarse el principal problema que las pasiones representaban para Platón cuando se trataba de enjuiciar el sistema político ateniense. Su caracterización en estas líneas, faltas todavía de la concreción y la complejidad psicológica que vendrá después, es muy precisa. Se destacan, efectivamente, dos rasgos que explican el lugar central que Platón va a conferirle a las pasiones. Pues, en primer lugar, nos dice Sócrates (493a 4), es una parte cuya naturaleza la convierte en una presa fácil de la persuasión y se deja

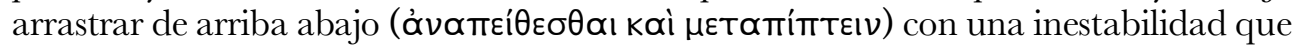
revela, por tanto, el sustento irracional en el que se basaba la política democrática ateniense. La segunda característica también está relacionada con la proyección política que Platón confiere a las pasiones en esta obra: es su condición inmoderada e insaciable (493b 2-3), que explica no pocos excesos de la democracia ateniense.

\footnotetext{
${ }^{2}$ Cfr. en este sentido, KAHN 1987, 80.
} 
Sería muy fácil encontrar episodios en la historia de la Guerra del Peloponeso que ilustrarían a la perfección estas dos características de la versión populista de la democracia ateniense criticada por Platón. Recordemos a este efecto, como ejemplo de la inestabilidad y la convulsión propias de una democracia radicalizada, lo que ocurrió en el 427 a.C., cuando la Asamblea, instigada por Cleón, aprobó una moción en la que se acordó dar muerte a todos los varones de Mitilene mayores de edad y reducir a la esclavitud a mujeres y niños. Al día siguiente se arrepintieron, porque, según nos cuenta Tucídides (III 36), se dieron cuenta de que la decisión de matar a una población entera, en lugar de actuar solo contra los culpables, era cruel y tremenda. En esta ocasión se impuso en la Asamblea la cordura de Diodoto y tuvieron que mandar otra trirreme para anular la orden anterior. En cuanto al carácter insaciable del démos alentado por los demagogos, Tucídides considera la pleonexía, la ambición desmedida e insaciable, una de las causas fundamentales de la derrota de Atenas en la Guerra ${ }^{3}$. Propuestas que obtuvieron el favor de la Asamblea como la expedición a Sicilia, promovida por Alcibíades (cfr. Th. VI 15, 2-3), demostraban este hecho sin dejar lugar a ninguna duda.

Estas dos características a las que hemos hecho referencia ponen en relación directa, por otro lado, la teoría platónica de las pasiones, que se anuncia en estas páginas del Gorgias, con los dos motivos fundamentales de la condena del populismo democrático ateniense que Platón realiza en la obra. Efectivamente, Sócrates alude a un hombre ingenioso, "de Sicilia o Italia", tal vez un pitagórico o un órfico, que hizo un juego de palabras y llamó a esta parte del alma píthon (tonel, 493a 7) a causa de

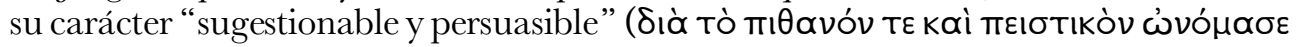
$\pi(\dot{\theta} \circ \mathrm{v})$. Como dijo Jaeger ${ }^{4}$, la democracia ateniense era "un estado retórico hasta la médula". Puede parecer un anacronismo hablar de una condena del "populismo" por parte de Platón, cuando este fenómeno es propio, rigurosamente hablando, de corrientes de pensamiento político que pertenecen al siglo XX. Pero en este punto concreto y en otros que veremos, hay analogías que nos permiten el empleo del término. No en balde algunos defensores del populismo han reivindicado el uso de la retórica como "instrumento de una racionalidad social ampliada", que puede constituir sin complejos "la anatomía del mundo ideológico" 5 . La crítica de la retórica en el Gorgias comprende muchos aspectos ${ }^{6}$, pero el punto de vista en el que ahora nos centramos es fundamental, pues Platón la acusa de dirigir la política ateniense por medio de unos mecanismos irracionales, que tienen como objeto "captar la

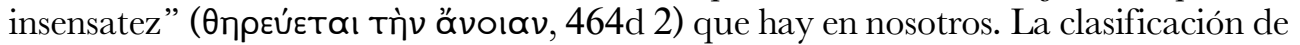

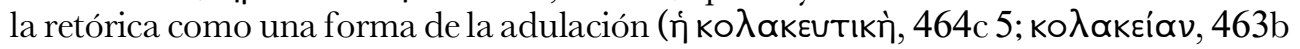
1, 464e 2 et passim), en la que la acompañan, como es sabido, la culinaria, la cosmética y la sofística, la pone en relación directamente con el placer concupiscible

3 Calonge Ruiz 1990, 79.

${ }^{4}$ JAEGER 1971, 546.

5 Cfr. Laclau 1994, 26-27.

${ }^{6}$ Cfr. Vallejo Campos 1993 y 2002. 
que es el objeto de las pasiones irracionales. La retórica es acusada, efectivamente, de "tener como objetivo lo agradable sin consideración de lo mejor" (тoũ ídéos

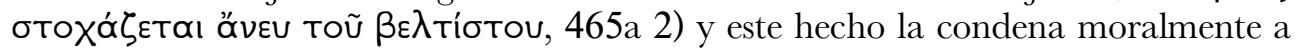
ojos de Platón con toda la amargura que encierra su convicción de que Sócrates fue juzgado en Atenas como lo sería un médico acusado por un cocinero ante un tribunal de niños (cfr. 521e).

Platón y Gorgias, el sofista que escribió el Encomio de Helena, pueden diferir profundamente a la hora de considerar la retórica una verdadera técnhē, pues Sócrates rechaza en este punto las pretensiones de la sofística y ve imposible que pueda

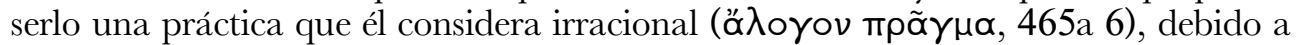
su desconocimiento de las verdaderas causas (465a 5 ) en las que se basan sus métodos. A su juicio, el fundamento retórico que tiene en la democracia ateniense la política convierte a esta en un simulacro de lo que debería ser. Pero, en lo que incumbe a nuestro tema, ambos coincidirían y en este otro sentido las páginas del Gorgias no traicionan el pensamiento del sofista: la retórica para persuadir tiene que operar por medio del engaño. Es el otro lado de una actividad, convertida en el modus operandi de la política, que no se dirige a la razón, sino a las potencias irracionales de la personalidad humana. Lo comprobamos en la frase que antes citamos de modo

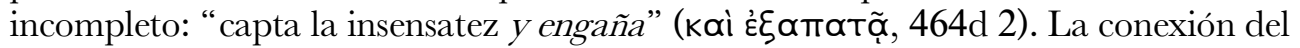
engaño (åmatŕ), en el que consiste la persuasión retórica según el Sofista de Leontinos (cfr. 82 B11, B11, B23 DK), con las respuestas emocionales del oyente era además muy clara. En su psicología del $\log _{0} \mathrm{~s}^{7}$, la persuasión era posible por la imposibilidad del saber que llena de incertidumbre los acontecimientos de la vida humana. En su lugar, el hombre solo cuenta con las "vacilaciones y la falta de certeza de la opinión" (cf. 82 B11 DK). En esto, como vemos, coincidía totalmente con Platón. Gorgias era consciente del poder de este "gran soberano" (cf. 82 B11 DK) que es el lógos, pero sabía que su poder de persuasión residía en su capacidad para provocar reacciones emocionales en el oyente, pues, como dice en el Encomio, "hace cesar el miedo, elimina la tristeza, produce alegría y acrecienta la compasión” (cf. 82 B11 DK).

La retórica, junto con la sofística, aparece, pues, en el Gorgias como un simulacro

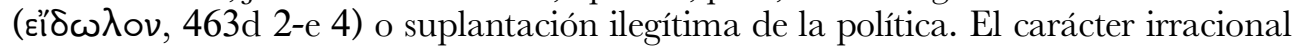
de la persuasión, que es, a juicio de Sócrates, donde reside el poder de la retórica del que Gorgias se enorgullece (cfr. 456a y sgs.), se ejerce sobre una multitud de gente ignorante, "a la que persuade, pero no instruye" (458e 7-459a 1). De ahí la importancia de las pasiones, que Platón tiene presente al evaluar la usurpación de la verdadera política por esta retórica capaz de movilizar todos los recursos emocionales para lograr sus propósitos. Al enjuiciar la política imperialista de los grandes estadistas mencionados en la obra, como Temístocles, Cimón, Milcíades o Pericles, Platón tiene

\footnotetext{
${ }^{7}$ Cfr. Segal 1962, 105 y sgs.; para la concepción de la persuasión retórica como un efecto mágico que seduce al alma, es clásico el estudio de De Romilly 1975, 4-21.
} 
muy en cuenta la liberación de las pasiones que latía bajo el fondo democrático de un régimen, a cuya descomposición asistió en medio de la derrota y los enfrentamientos internos. "Hablar ante el pueblo, practicar la retórica y ejercer el gobierno" del modo en que se hace en la democracia ateniense (500c 5-6), bajo el esquema de una política adulatoria que consigue el poder en la medida en que sabe granjearse el favor del démos, tenía como contrapartida operar de un modo que no podía consistir sino en "satisfacer las pasiones propias y ajenas" (тò Tàs ह̇mı

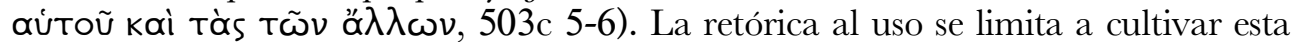

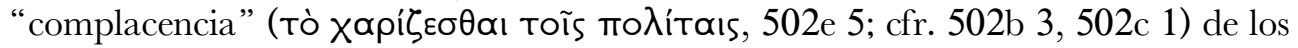
ciudadanos que apela a sus pasiones procurándoles el placer de satisfacer sus deseos con una total despreocupación del bien (cfr. 501d 4). Independientemente de los resultados, que serían elogiables para una Realpolitik, Platón condena una acción de gobierno, iniciada en el pasado glorioso, que ha hecho a los atenienses mucho peores de lo que eran (515e 5-6). Causa asombro a Calicles, el famoso personaje del Gorgias, que Sócrates se atreva a impugnar la política practicada por los grandes estadistas del imperio que engrandecieron a Atenas. Pero, aun admitiendo que han sido mejores servidores que los políticos de su tiempo, a su juicio, abrieron un camino que ha llenado la ciudad de construcciones y tributos innecesarios "al margen de la moderación y la justicia” (519a 2). Han fracasado igual que los políticos del presente, al no ser capaces unos ni otros de "transformar las pasiones de los ciudadanos ni dejar de ser condescendiente con ellas" (517b 5).

Con la irrupción de las pasiones como un factor antropológico de importancia extraordinaria y la experiencia amarga que Platón ha extraído del modo en que se habían adueñado de la escena política ateniense, aparece en los diálogos un nuevo Sócrates ${ }^{8}$. Ya no se trata de ejercer el cuidado del alma con ciudadanos que se prestaran voluntariamente a recibir la terapia socrática de los "bellos discursos", con los que se implanta la moderación en las almas, según se decía en el Cármides (157a 4-5). Tampoco parece suficiente con "informarlos y persuadirlos", como afirma el optimismo intelectualista de Sócrates en la Apología (35c2). Ahora el enfermo, efectivamente, no es el individuo, sino la ciudad, porque es esta la que se ha vuelto enferma y está llena de úlceras supurantes y emponzoñadas (Grg. 518e). Ahora caemos en la cuenta de la importancia que tienen las pasiones para el pensamiento platónico y comprendemos la transformación que ha tenido el proyecto intelectualista de Sócrates. Antes, este confesaba que rehuía la política (cfr. Ap. 32e), por las advertencias de su señal demónica, y ejercía su método en una escenario puramente privado. Pero ahora Platón le hace decir (Grg. 521d) que "es uno de los pocos atenienses, por no decir el único, que practica el verdadero arte de la política en la actualidad”. El Sócrates de estos diálogos posteriores se ha dado cuenta de que la terapéutica y el cuidado del alma debe practicarse en un escenario político: hay que "persuadir a los ciudadanos", pero también, y esta es la novedad, "obligarlos"

${ }^{8}$ Cfr. Vallejo Campos 2016, 232 y sgs. 


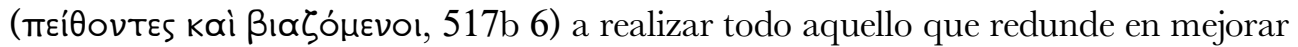
su condición emocional. Interrogar y refutar a los interlocutores ya no es suficiente. El punto de partida viene determinado en este momento por la conciencia que tiene Platón de que Atenas es una ciudad enferma, debido a la forma en que los supuestos estadistas del imperio han "obsequiado suntuosamente" a sus ciudadanos con todo lo

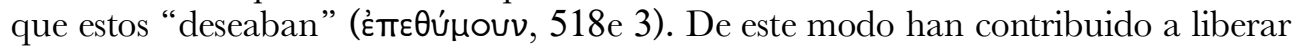
unas pasiones destructivas que se mostrarán en todo su dramatismo cuando estalle "el ataque de la enfermedad" (519a 4). El proyecto filosófico socrático ha experimentado, al hilo de la importancia que adquieren las pasiones, una transformación de no poco alcance, porque la filosofía, que antes tenía como objeto el cuidado del alma, ahora se llama política y es a esta a la se le encomienda la terapia que ha de emplearse, de manera que, como ha afirmado algún comentarista con razón, parafraseando a Clausewitz, la filosofía es la continuación de la política por otros medios?

Como hemos visto antes, el empleo del término populismo para referirnos a la crítica que hace Platón de la democracia puede parecer anacrónico, pero se ha dicho que el populismo se caracteriza por "una política comunicativa dirigida al afecto y al sentimiento" y que su ideología es "contraria a la idea ilustrada" de un sujeto racional ${ }^{10}$. En el espectro ideológico de pensadores populistas actuales, se critica las teorías políticas que privilegian la racionalidad, porque, a juicio de autoras como Mouffe, "dejan de lado un elemento esencial, que es el rol crucial que juegan las pasiones en asegurar la lealtad a los valores democráticos"11. Si es así, estamos comprobando, por lo visto en el Gorgias, que el examen platónico de la democracia se inscribe en una crítica del populismo que apunta en esa dirección. Como vamos a ver en la República, Platón era un crítico de la democracia, porque lo consideraba un régimen en el que, en determinadas circunstancias, como las que él conoció en los primeros treinta años de su vida, se exaltan las pasiones, se olvidan las instituciones que oponen un freno a las decisiones precipitadas e irracionales de la multitud y se pierde el respeto a las leyes, como si todo fuera posible en una toma de decisiones en la que decide el pueblo alentado por los líderes que no respetan ningún principio de contención. Sócrates se ríe amargamente del "amor al pueblo" (513c 7) que atribuye a la acción política de los líderes atenienses. A la política concebida como adulación y a la liberación de las pasiones que ello lleva consigo opone el ideal del político como un médico cuyo arte es capaz de extirpar las pasiones que traen la destrucción y la corrupción de la democracia ateniense. Se anuncia así la figura del filósofo gobernante, que aparecerá en la República, como un médico cuya misión fundamental consistirá en curar una ciudad enferma por medio de una adecuada purgación de las pasiones.

${ }_{9}^{9}$ Cfr. V. Magaslhaes-Vilhena, Socrates et la légend platonicienne, París 1952, 128 apud DodDs $1959,384$.

10 Cfr. Villacañas Berlanga 2015, 46-47.

11 C. Mouffe apud Laclau 1994, 212. 


\section{La República}

2a. La purgación de las pasiones y el estado ideal. La sofística y la irracionalidad del estado

En la República podemos comprobar con todo lujo de detalles la centralidad que corresponde a las pasiones en el pensamiento ético y político de Platón. Desde el punto de vista que nos ocupa, hay muchos elementos de coherencia en el planteamiento que nos ofrecen los diálogos, desde el Gorgias a las Leyes pasando por la República. Piense el lector en la definición de la injusticia que nos proporcionan las Leyes (IX 863e 6864a 1): «denomino injusticia en general a la tiranía en el alma del coraje y el miedo, el placer y el dolor, las envidias y los deseos» (દ̇mı̈uníaıı; trad. de F. Lisi). En realidad, se trata de un planteamiento muy similar al que encontramos en el Gorgias, pues aquí, como sabemos, Calicles representa la antítesis y el verdadero reto al que se enfrenta Platón, ya que encarna al político sin escrúpulos que defiende, frente a la contención de las pasiones y la moderación, "la molicie, la intemperancia y la libertad" como fundamentos de la verdadera "virtud y la felicidad" (492c 4-5). De manera que no nos puede extrañar que Calicles, en concordancia con ello, sostenga que es mejor cometer injusticia antes que sufrirla y, por tanto, que el que quiera vivir rectamente, desde el punto de vista de la naturaleza, debe "permitir que sus pasiones sean las más grandes que sea posible" y estar dispuesto a "servirlas con valentía e inteligencia" (491e 8-492a 2). Por el contrario, en esta obra, como sabemos, la justicia consiste en un "kósmos" (cfr. 508a 2-3) basado en la moderación, en la que corresponde a la razón establecer un límite a la satisfacción de las pasiones.

Se comprenderá, por tanto, que en la República, al plantear las bases del estado ideal haya que hacer un diseño de la ciudad basado fundamentalmente en una purgación de las pasiones. El lugar central de este tema en la obra podemos examinarlo a la luz de las tres ciudades a las que se pasa revista: "la ciudad de los cerdos", "la ciudad lujosa", y la ciudad ideal, que nace de una purificación de la anterior (cfr. 399e). Desde el punto de vista que estamos indagando, las tres pueden describirse en términos de necesidades y deseos con sus correspondientes consecuencias pasionales. La "ciudad de los cerdos" (372d 4), que se denomina así a partir de la calificación que hace Glaucón de la ciudad que Sócrates acaba de describir, es un ideal caracterizado por una simplificación de las necesidades y un rigorismo moral inalcanzable para la mayoría de los seres humanos. Aunque Glaucón la denomine así,

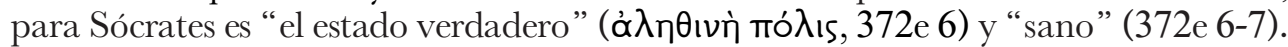
Pero, debido a su primitivismo y su simplicidad excesiva, no la toma verdaderamente en serio y construye a continuación, ante los ojos de sus interlocutores, "una ciudad

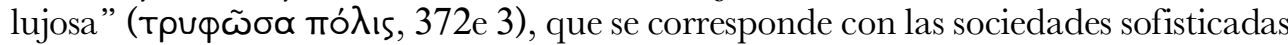
que existen en el momento. Esta segunda ciudad puede caracterizarse como una forma de comunidad que "sobrepasa el límite de las cosas necesarias" (373d 10): los deseos superfluos y las pasiones generadas de esta forma traen como consecuencia la lucha por una "posesión ilimitada de riquezas" (373d 9-10), lo cual lleva consigo que 
estas ciudades se enfrenten entre sí. Se destruye así la armonía y la sana simplicidad de la ciudad originaria, que no vivía "por encima de sus recursos" (372b 8). Aquí habrá toda clase de tipos humanos, para satisfacer los deseos y necesidades admitidos, y nos encontraremos con modistos, peluqueros, imitadores y poetas, pero sobre todo con médicos (373d), como corresponde a una ciudad afiebrada, que necesita de ellos para curar las enfermedades que surgen de este tipo de vida. La consecuencia de todo ello será el nacimiento de una actitud imperialista que llevará a estas ciudades a la necesidad de "amputar el territorio vecino" (373d 7) y de esta manera aparecerá la obligación de mantener un ejército que proteja a la ciudad de las injerencias vecinas.

El punto de partida de la ciudad ideal, como solemos denominar a la Kallipolis descrita en la República, es, pues, esta ciudad afiebrada o enferma ${ }^{12}$, en la que la proliferación de médicos y jueces en la vida pública es el signo inequívoco para Platón de que estamos ante el mismo estado emponzoñado descrito en el Gorgias. De ahí que la ciudad ideal deba construirse sobre una purgación de estas necesidades superfluas que llevan consigo la patología social. La purificación del estado lujoso que hay que operar debe conducir a "un estilo o régimen de vida" (Síaıta, 404d 11), que sea promovido por una reglamentación de la gimnasia y la música, para huir de la

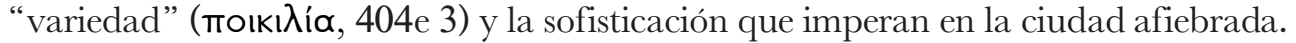
La simplicidad, la sencillez y la austeridad, favorecidas por la educación, conducirán a la salud del cuerpo y la moderación del alma. Cuando comprobamos que el objetivo fundamental de toda la reglamentación educativa en el estado ideal obedece al

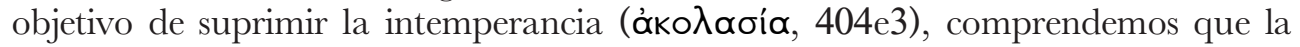
purgación consiste sobre todo en una simplificación de las necesidades y, sobre todo, en una eliminación de las pasiones más perjudiciales, a las que Platón atribuye el origen de todos los males en los estados griegos. La purgación efectuada sobre la ciudad del lujo eliminará el exceso y todo aquello que, por su excitación de las pasiones, pueda conducir a un estilo de vida inmoderado. En los libros II y III se describen "las pautas" ( $412 \mathrm{~b} 2$ ) de la educación elemental destinadas a poner las bases de la formación de los futuros gobernantes y se inicia así un proceso de largo alcance en un planteamiento que admite la naturaleza humana tal como es, sin idealizarla, pero tampoco sin renunciar a una poda de todas aquellas pasiones que ponen en peligro el bienestar de la ciudad ideal. Efectivamente, la cosa en este sentido no termina aquí, porque aún se hace más terminante en la selección de los guardianes y en las etapas posteriores de su formación superior.

Las pruebas para la selección de los gobernantes tienen por objeto encontrar a aquellas personas que pongan por encima de todo el interés del estado. Se trata de

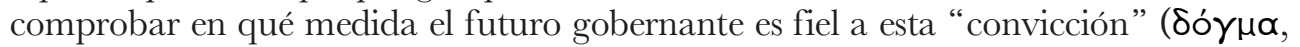

\footnotetext{
12 Para el vocabulario médico empleado en estos pasajes de la República y la crítica de la medicina practicada en la ciudad del lujo, cfr. VEGETTI 1995, 81 y sgs., y 1998, 431-436. Sobre el sentido que tiene en la obra "la medicina política", con la que Platón quiere corregir los excesos de la nosotrophía o el cuidado excesivo prestado a los enfermos en las ciudades contemporáneas, cfr. VALLEJO CAMPOS 2018, 87 y sgs.
} 


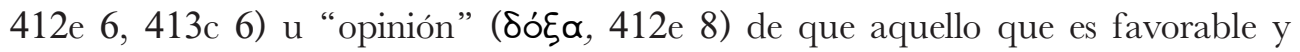
conveniente para el estado lo es también para él. Recordemos entre ellas "la prueba de hechicería" (yonteía, 413d 7), en la que deberá mostrar su capacidad de resistir ante el embrujo que provocan en el pensamiento el placer o el temor y las pasiones con ellos relacionadas. El futuro gobernante debe demostrar, como ya se estableció en el Gorgias (491d 7-8), que es capaz de "gobernarse a sí mismo", lo cual no significaba allí otra cosa que el control de las pasiones. Aparte de la implicación política que esto tiene, comprobamos también la relación directa que Platón establece entre las emociones y los aspectos más directamente cognitivos que determinan el conocimiento humano. En la República estas pruebas están orientadas a probar que el futuro gobernante no abandonará sus convicciones por influencia de las pasiones. Recordemos a este efecto, "la hechicería", que se describe en el Fedón, de las almas

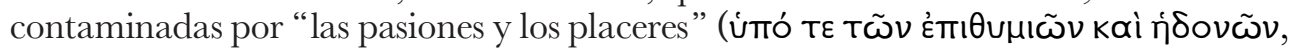
81b 4), que solo consideran verdadero lo que tiene una naturaleza corpórea.

La purgación del futuro gobernante tendrá que proseguir en etapas futuras de su formación superior. Será necesaria, efectivamente, una especie de "poda" de todos los factores pasionales que puedan comprometer su naturaleza racional. A ello se alude en la explicación que da Sócrates de la alegoría de la caverna, cuando se mencionan "la glotonería y los placeres de esa índole" corporal que impiden al alma

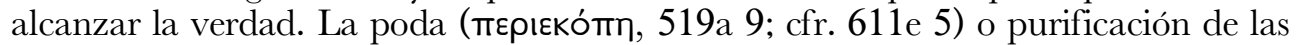
pasiones que hay que practicar en la ciudad ideal tiene, por tanto, su perfecta correspondencia en el futuro gobernante, que también tendrá que someterse a ella. La presencia de laspasiones "en una naturaleza de esta clase" (519a 8), como la que corresponde al perfecto guardián de la ciudad ideal, nos permite comprender que "el ascenso" (’̛́vóßaoı), en el que insiste el lenguaje alegórico utilizado (cf. 515e 7, 517a $3,517 \mathrm{~b} 4,519 \mathrm{~d} 1$ ), no pueda realizarse sin una cierta dosis de violencia (bía, 515e 6) y compulsión, con las que hay que arrastrar al prisionero liberado para que pueda finalmente abrir los ojos y ver "la luz". Esta presencia paradójica de la compulsión o la violencia, incrustada sobre un fondo filosófico de intelectualismo socrático que no armoniza bien con ella, indica en qué medida Platón ha tenido en cuenta la fuerza poderosa de las pasiones. Dominarlas e integrarlas en un "orden” diseñado por la razón, como hemos visto, es fundamental para lograr la justicia que se construye en la República para el individuo y el estado de acuerdo con las reglas del isomorfismo estructural que rige los dos ámbitos.

Como estamos viendo, el planteamiento del Gorgias y la República tiene muchas similitudes, aunque solo en esta última obra se desarrolla la idea de un arte del estado, que era el ideal normativo desde el que se criticaba en el primero de estos diálogos la usurpación de la política, encarnada en la sofística y la retórica. Desde el punto de vista de las pasiones, se explicitan ahora, como estamos viendo, dos condiciones fundamentales del arte del estado. Este consiste, como establecía el Gorgias, en una téchne, pero, para estar en posesión de las condiciones intelectuales exigidas, a las que se accede solo después de un largo proceso de formación científica y dialéctica, es 
necesario un dominio de todos aquellos elementos pasionales que puedan comprometer la acción de gobierno. A ello se encaminan no solo muchos factores del mismo proceso de formación de los guardianes, sino la concepción misma del estado, en el que se prohíbe, como sabemos, la propiedad privada a los que están encargados de ejercer el poder. Pero, en segundo lugar, las pasiones deben tenerse presente en el momento de operar sobre la sociedad, ya que el filósofo gobernante tiene que actuar como un médico que trata a una sociedad enferma, prescribiendo, como se anticipaba en el Gorgias (cfr. Grg. 505a 6), qué pasiones está permitido satisfacer y prohibiendo las que han sido excluidas del estado ideal.

En la República, Platón matiza un tanto la crítica de la sofística que se había expresado con tanta virulencia en el Gorgias, porque no se les ve como causantes, sino más bien como cómplices y esclavos de una sociedad que ellos solo han contribuido a complacer. Por lo demás, las coincidencias son muy grandes. La sofística se precia de haber alcanzado "la sabiduría" ( $R$. 493a 9), pero, en realidad, esta consiste en conocer "las convicciones de la multitud". Platón se enfrenta, desde luego, a la ideología dominante de la democracia ateniense, que se amparaba en esa "peculiar combinación de consenso y coerción", que el populismo moderno ha visto, siguiendo a Gramsci, en el concepto de "hegemonía"13. Para la sofística solo cuentan las creencias y opiniones de aquellos a los que dirige su discurso persuasivo, pues la retórica niega la existencia de lo que Platón considera el verdadero arte del estado. En la imagen de la nave del estado (487e y sgs.), el patrón, que representa al pueblo ateniense, y los marineros, que son un trasunto de los políticos al uso, coinciden, efectivamente, en su creencia de que no existe un arte o una técnica ( т́́x $v \eta$, 488b 5) de la navegación que pueda enseñarse. Su lugar lo ocupa ilegítimamente esta sabiduría suministrada por la sofística, la cual no consiste sino en conocer "los impulsos y pasiones" (Tàs ópyós kå̀ غ̇mıUuías, 493b 1) de esta "bestia grande y fuerte", que es el pueblo ateniense. Pretende estar en posesión de "una sabiduría" y "un arte", cuando en realidad no sabe distinguir, a juicio de Platón, qué hay de bello, bueno y justo en "tales

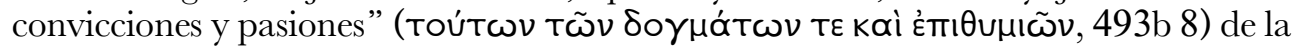
multitud.

Antes de abandonar estos pasajes del libro VI, debemos tener presente no solo la dosis de adulación implícita en ese modus operandi, sino también la violencia que comporta tal estado de cosas en la navegación de esta nave atribulada que es la democracia ateniense. Platón nos muestra que, detrás de la falta de un gobierno racional, hay una violencia que se manifiesta abiertamente cuando alguien se atreve a esgrimir los derechos del arte del estado. Los marineros no solo ridiculizarían como

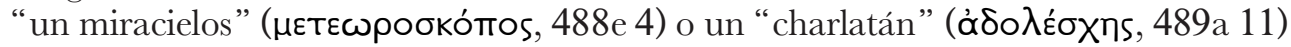
al que defendiera la necesidad de un arte de la navegación, sino que, llegado el caso, estarían dispuestos a descuartizar al que afirmara que puede enseñarse y no dudarían en arrojar por la borda al que se atreviera a discutirles el gobierno de la nave basándose

${ }^{13}$ Cfr. Laclau 1994, 84. 
en tales argumentos (488b-c) ${ }^{14}$. El papel ridículo del filósofo en el estado ateniense no se debe, pues, a una cuestión de derecho, sino a una situación de hecho, que revela la incompatibilidad de la ciencia y el arte del estado con la ideología hegemónica que defienden los demagogos en la democracia radicalizada que Platón conoció a finales del s.V a.C.

2b. Del estado ideal a la tiranía: alejamiento de la razón y liberación de las pasiones

En los libros VIII y IX de la República se pasa revista a la degeneración de la ciudad ideal, que es el estado establecido "en conformidad con la naturaleza" (444d 9), siguiendo una secuencia que se inicia con aquella y continua con la timocracia, la oligarquía, la democracia y, finalmente, con la tiranía. Se trata de formas degeneradas respecto a las exigencias normativas que representa "el estado perfectamente bueno" (427e 7), definido en la teoría de la justica expuesta en el libro IV, por lo que Platón

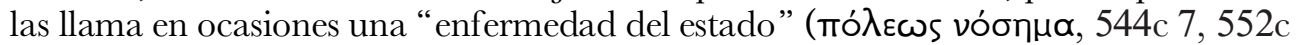
4, 564b 1). Esta secuencia, como han señalado los especialistas ${ }^{15}$, en la que se describe la transformación de unos regímenes en otros, no debe entenderse como una narración histórica o una teoría política acerca del desenvolvimiento de los sistemas políticos, sino más bien como una secuencia lógica en la que se interpretan las diferentes formas de gobierno en términos de un progresivo alejamiento de la razón. La cuestión de las pasiones está, por tanto, íntimamente relacionada con dicha secuencia, porque nos sirve para evaluar el grado en el que, a juicio de Platón, se produce una quiebra respecto al ideal normativo que representa la Kallipolis descrita en la República.

No es necesario exponer ahora con todo lujo de detalles la teoría de la justicia en la ciudad ideal ${ }^{16}$, pero debemos recordar que el esquema de la oikeiopragía (432c 8) en la que se basa no solo atribuye funciones específicas a cada clase del estado y a cada parte del alma, sino que también establece un orden en el que las virtudes (sabiduría, valor, moderación) dependen específicamente de la relación que las diferentes pasiones deben guardar con la razón. Cada parte del alma tiene sus pasiones y sus placeres propios, así como cada clase del estado sus legítimos intereses. El hombre y el estado "perfectamente buenos" no suprimen las pasiones, pero las someten a un estatuto diseñado por la razón, en el que cada una de estas cumple teleológicamente con su cometido para alcanzar la perfección que corresponde al todo al que pertenecen. La ciudad "perfectamente buena", tal como Sócrates la define, es un estado "sabio, valiente, moderado y justo" (427e 10-11). Desde el punto de vista de las pasiones, esto no significa, desde luego, que pueda darse rienda suelta a todas, sino que "sobre las pasiones de la multitud de gente mediocre han de prevalecer las

14 Algunos comentaristas han visto en ello una alusión al destino trágico de Sócrates; cfr., p. ej., GASTALDI 2003, 198. Para Adam (ad locum), en cambio, puede tratarse meramente de una alusión a las luchas encarnizadas que acaban en la muerte o el exilio de los contendientes políticos.

${ }^{15}$ Cfr. BARKer 1961, 283-285, SCHOFIELD 2006, 106-107.

16 Cfr. Vallejo Campos 2108, 101-109. 


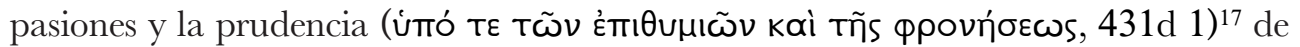
aquellos que son menores en número, pero más capaces" (trad. de Eggers, levemente alterada). Deberíamos resaltar a este efecto que la moderación, a diferencia de las otras dos virtudes de la ciudad justa (la sabiduría y el valor), no reside solo en una clase, sino en la totalidad del estado, pues consiste en una harmonía (431e 8) o concordia (ónóvoı́, 432a 7), que se sustenta en una coincidencia de opinión (431d

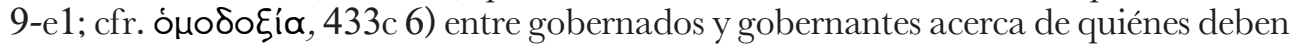
mandar. Pero esto no significa otra cosa sino que unos y otros deben estar de acuerdo en el orden al que debe ajustarse la satisfacción de sus pasiones para el bien del estado del que forman parte.

La descripción de las pasiones en términos axiológicos explica que el estado ideal pueda ser denominado legítimamente una aristocracia, porque en él estarán al mando "unos pocos" ciudadanos, que son "los mejores" por naturaleza, debido precisamente

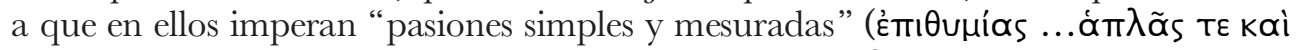

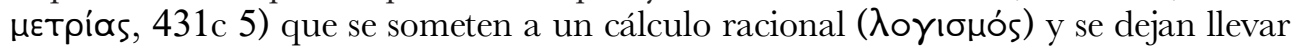

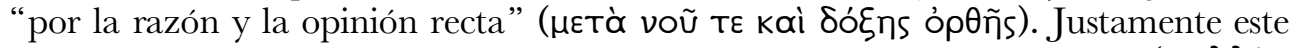

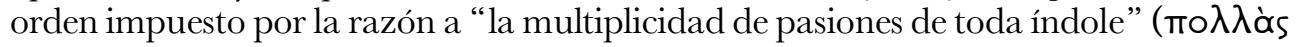

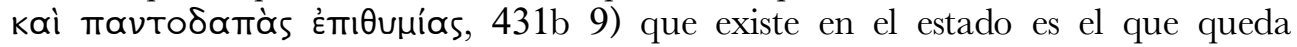
subvertido con la degeneración de la ciudad ideal que se produce en la secuencia que hemos mencionado. En la aristocracia están al mando unos "guardianes perfectos" (428d 7) que encarnan la sabiduría del estado (428e 7-9). En ellos predomina como fuerza motivacional su amor al conocimiento, pero además han sido educados para actuar en todo momento conducidos por la razón, sin atender a ninguna otra consideración.

De la aristocracia pasamos a la timocracia, un régimen en el que muchos comentaristas han visto grandes semejanzas con el sistema político espartano. Platón está convencido de que se trata de una cultura para la guerra muy por debajo del régimen ideal donde se halla la verdadera virtud basada en el dominio de la razón. Por esta razón, en la timocracia la virtud no está basada en la persuasión, sino en la fuerza (úmò ßías, 548b 7), ya que, por deficiencias en la formación de estos guardianes, ha perdido de vista "los argumentos y la filosofía" (548b 8-c 1) que son los únicos fundamentos de la virtud verdadera. La timocracia es un régimen en el que el elemento fogoso o colérico del alma, que predominaba en la clase de los militares, propia del estado ideal, se impone a la razón. En consecuencia, la motivación fundamental de este régimen es el afán de victoria y el ansia de honores (

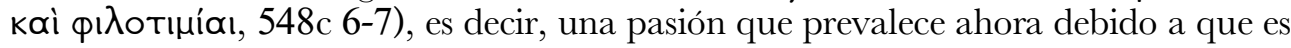

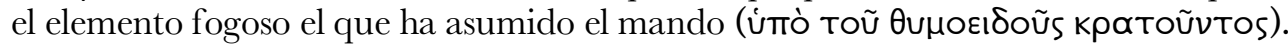

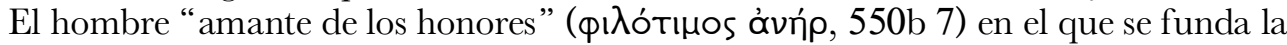
timocracia es un tipo, efectivamente, dominado por la parte fogosa del alma, cuyo

${ }^{17}$ Hay quien ha visto no sin razón en esta expresión una cierta hendíadis, como VeGETTI (2000, 184), pero no debemos olvidar que en la clase dirigente, donde reside la virtud de la prudencia, hay también pasiones, aunque prevalezcan en ella las que son propias del alma intelectiva. 
placer dominante consiste en la obtención del reconocimiento o la timé que da nombre al régimen.

Sin embargo, junto a esta parte irracional del alma y el consiguiente predominio de su pasión característica, comienza a aparecer, como un segundo rasgo del régimen, el deseo de riquezas o philochrēmatía, que es una motivación atribuida a la parte apetitiva del alma, donde residen los deseos propiamente concupiscibles. Cuando Platón explica el advenimiento del tipo humano que prevalece en este régimen, nos

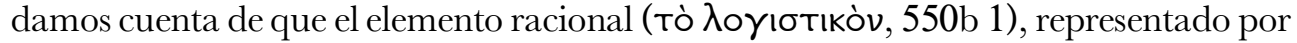
el padre, es postergado a favor de un compromiso entre las partes irracionales,

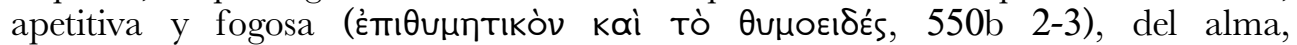
representadas a su vez por otros sujetos que están a su alrededor. Esto explica "la virtud" imperfecta propia de este sistema político ${ }^{18}$. No podemos detenernos con más detalle en las características de este régimen, pero anotamos en qué medida la utopía de la ciudad ideal, al establecer un criterio normativo basado en la razón, sirve para enjuiciar los regímenes existentes desde el punto de vista de las pasiones que ponen en juego.

Con la oligarquía, damos un paso más allá en el alejamiento progresivo de la razón que esta secuencia viene a describir. Aunque etimológicamente es "el gobierno de los pocos" (Hdt. III 81), para Platón hace referencia a una plutocracia o régimen basado en la tasación de la fortuna (550c 11), lo cual explica que, a su juicio, ahora es la parte concupiscible la que se ha adueñado del alma, pues el deseo de riquezas es su motivación fundamental, al depender de estas la satisfacción de los deseos concupiscibles. La decepción que produce en los jóvenes las injusticias en el reparto de los premios y, a veces, la suerte desgraciada que corresponde a los virtuosos en un régimen timocrático hace que los ciudadanos se vuelvan a la riqueza como el nuevo ideal $(553 \mathrm{a}-\mathrm{c})$. La pasión por el dinero existía en la timocracia, pero allí estaba controlada por el deseo de honor, que era su motivación principal, y, en consecuencia, la posesión de riquezas se mantenía en secreto. En cambio, ahora se hace pública y con ello se extiende la estimación de la riqueza, lo cual, unido a la falta de educación, hace surgir en este tipo de hombre deseos concupiscibles que acrecientan la fuerza de lo apetitivo en el alma. A raíz de los tres regímenes (oligarquía, democracia y tiranía) que se suceden después de la timocracia, Platón estudia las complejidades de la parte concupiscible del alma que prevalece en ellos y el carácter de las pasiones que se van apoderando de la sociedad en tales sistemas políticos. A propósito de estos, Platón realiza una clasificación de las pasiones, en la que va a distinguir tres tipos diferentes de apetitos, deseos o pasiones: los necesarios, que predominan en el régimen oligárquico, los innecesarios, que se abren paso en la democracia, y, dentro de estos últimos, los que tienen una naturaleza criminal o "contraria a toda norma", que triunfan en la tiranía.

18 Cfr. Vallejo Campos 2018, 247-251. 
El ideal de un estado perfectamente bueno y del "hombre regio" que lo encarna, basado en la razón y el control de las pasiones, sirve de norma para juzgar la desviación de los demás regímenes políticos en términos de las pasiones que prevalecen en ellos. La clasificación axiológica de tales regímenes queda determinada por el grado de irracionalidad de los apetitos que los caracterizan. En la oligarquía, tenemos el grado menor de irracionalidad pensable en un régimen que obedece al principio del lucro, propio de la parte apetitiva. Aquí triunfan deseos pertenecientes a esta parte, en lugar de la razón y el principio del honor, característicos de la aristocracia y la

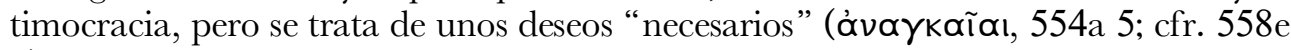
1 ), porque no pueden eliminarse y contribuyen positivamente a satisfacer las necesidades de la vida, como la sed y el hambre. Desde un punto de vista político, para un régimen como el oligárquico, que mantiene a raya los demás apetitos, tienen un efecto incluso positivo, porque son productivos para la actividad económica y no son despilfarradores (559c). Los demás deseos, peores e innecesarios, también existen en el alma oligárquica de este régimen, pero este tipo de hombre consigue reprimirlos.

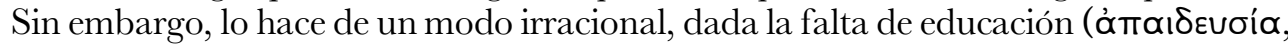
554b 8) que padece: es incapaz de "persuadir" a estos otros deseos del mal que representan y solo consigue imponerse por medio de "la razonable violencia" que subsiste en él. Esta irracionalidad que impera en el alma oligárquica, en la que los deseos necesarios solo triunfan por medio de "la coerción y el miedo" (ává $\gamma$ kṇ kaì фó $\beta \omega, 554 \mathrm{~d} 2-3$ ), es la que se impone también en el régimen político, ya que este solo logra instaurar el principio de la riqueza en el que se basa por medio de la fuerza armada y el temor (551b 3-4). Desde ese punto de vista, falta ya la concordia y la unidad del alma que se logra con la verdadera virtud, pues el alma oligárquica queda dividida en dos, de la misma manera que la polis ha perdido la unidad propia de la verdadera politeía y queda escindida en dos estados, el de los ricos y el de los pobres, que se enfrentan y conspiran constantemente los unos contra los otros (551d).

$\mathrm{El}$ advenimiento de la democracia, a partir de la oligarquía, surge precisamente con el triunfo de los pobres. Podemos dejar de lado muchos detalles de esta visión, sin duda exagerada y caricaturesca, que tiene Platón de la democracia, a veces más parecida a la que ofrece la comedia, como han mostrado los comentaristas ${ }^{19}$, que a una descripción desapasionada y equilibrada de los hechos históricos. Tampoco podemos entrar en la clave económica de su análisis, pero el paso de uno a otro régimen ${ }^{20}$ viene determinado por una concentración de la riqueza y un empobrecimiento de la población que conduce a una situación de conflicto, en la que acaban triunfando los pobres. Lo importante es tener presente los principios que quedan instaurados en el nuevo régimen, dado el paralelismo que se establece con las motivaciones pasionales que prevalecen en él. La libertad y la igualdad son los valores fundamentales en el sistema político ateniense, como Pericles pone de manifiesto en

${ }^{19}$ Cfr., p.e., Bertelli 2005, 390, Schofield 2006, 111.

${ }^{20}$ Cfr. CAMPeSe 2005, 217-218. 
su Discurso fúnebre (cf. Th. II 37, 2-3). Sócrates afirma que la libertad (562b 12) es para la democracia su bien más preciado y, por tanto, aquello que la define como tal. Esta eleuthería viene a concretarse en dos aspectos que el propio régimen democrático considera valores fundamentales: la libertad de palabra (mappnoía) y "la licencia

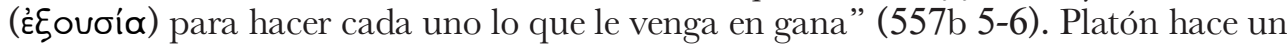
análisis en paralelo de la situación política y de los modos de vida y pasiones que se ponen en juego gracias a la constitución democrática. La consecuencia directa del carácter licencioso del régimen es el pluralismo característico de este estado, en el que insiste la crítica platónica cuando se refiere a la "variedad" (557c 1) y "el manto multicolor" (557c 5) de tipos y caracteres humanos ( cracia. Este pluralismo de modos de conducta al que Platón se opone representa, desde luego, una ruptura de la unidad y la simplicidad del ideal humano que exige el estado ideal. El paso de la oligarquía a la democracia ocurre cuando aflora una diversidad de conductas y estilos de vida que no es más que el trasunto de la variedad y la multiplicidad de placeres y pasiones accesibles al hombre que surge en este régimen (559d 9). Pero dicha diversidad se introduce en el sistema político a la vez que la falta de criterio para distinguir entre los pareceres del sabio y los de "mujeres y niños" (557c 8). La consecuencia es una constitución que viene a ser "agradable", pero igualmente “anárquica y polícroma” (558c 4-5).

Hemos visto que el hombre oligárquico privilegiaba los deseos necesarios de la parte concupiscible en detrimento de las demás (553d) y reprimía por la fuerza los deseos innecesarios $(554 \mathrm{c}-\mathrm{d})$. Ahora, esta falta de criterio que se impone al unísono del pluralismo democrático tiene como consecuencia que todos los placeres están en pie de igualdad (eis íoov, 561b 2). Por ello, en la sociedad democrática y en el alma del tipo humano que le corresponde, reina una "poliarquía”, como la llamó Barker21, en la cual, ante la falta de un principio dominante, hay una multitud de deseos que se disputan el poder. La igualdad de los ciudadanos que rige el sistema democrático de gobierno se traslada al alma del hombre individual, de manera que es una cuestión de

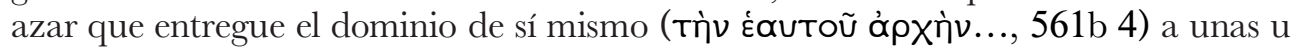
otras pasiones, ya que las alimenta por igual ( $\dot{\xi} \xi$ loov, 561b 5, c 4) sin un criterio que le permita distinguir entre "los placeres provenientes de (pasiones o) deseos nobles y

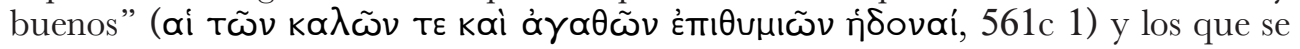
derivan de deseos perversos. Su falta de educación es responsable de esta ausencia de criterio y el verdadero motivo por el que alma carece del argumento o lógos verdadero (561b 7) que le permitiría distinguir entre unos y otros, a diferencia de lo que ocurre en el régimen aristocrático basado en la auténtica virtud.

Respecto a estos pasajes, a mi juicio, es muy interesante anotar, a propósito del pluralismo indiscriminado de las pasiones que se abre paso en la democracia, tanto la situación de conflicto que se desencadena entre los deseos, como su contrapartida cognitiva, ya que ambos factores hablan muy a las claras de la determinación social

\footnotetext{
${ }^{21}$ Cfr. BARKER 1961, 294.
} 
que tienen las pasiones y su conformación por una ideología que el populismo del régimen quiere transformar en un punto de vista hegemónico. Algunos autores han analizado $^{22}$ los elementos cognitivos que permiten a las pasiones convertirse en valores dentro del conflicto que tiene lugar entre las diversas motivaciones e intereses que están en disputa. Dejemos constancia ahora de que esta transformación de las pasiones en los valores dominantes tiene como condición de posibilidad "los discursos y

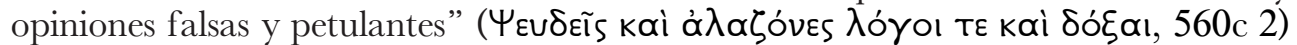
que acompañan a tales deseos. "La acrópolis del alma" en el joven que experimenta el asalto de este laberinto de pasiones está "vacía de conocimientos y preocupaciones

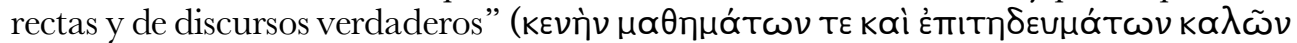
kaì $\lambda o ́ \gamma \omega \nu$ á $\lambda \eta \theta \tilde{\omega} \nu, 560 \mathrm{~b} 8)$ y no puede, por tanto, oponerse a la influencia dominante que quiere "llamar" "idiotez" al pudor o "falta de virilidad" a "la moderación" (560d 3). En este conflicto hay protagonistas, los líderes políticos o demagogos, que Platón llama "zánganos con aguijón” (564b 7), pero también están, en segundo lugar, los zánganos sin aguijón que pueblan las asambleas: ellos son la cobertura mediática de esta ideología que se pretende hegemónica, porque, según nos dice Sócrates (564d-e) "zumban en la tribuna” y no toleran que se diga otra cosa contraria a la política promovida por los otros. Dada esta superestructura ideológica, la situación de conflicto ya no puede considerarse solo un enfrentamiento de pasiones ciegas, porque estas han sabido dotarse de las representaciones que las presentan como los verdaderos valores por los que debe regirse la política. El carácter agonístico en el que se enfrentan las pasiones y los supuestos valores que están en juego se pone de manifiesto, cuando Platón afirma que en esta situación de stásis que vive la comunidad son tales "discursos los que prevalecen en el combate" (560d 1).

De la democracia a la tiranía se produce un agravamiento con el que se alcanza la distancia máxima que Platón quiere representar entre el hombre mejor, que vive en el régimen aristocrático de la ciudad ideal, y el peor, que es el tirano convertido en lobo $(565 \mathrm{~d}-\mathrm{e})$ y dominado por las peores pasiones que se puedan imaginar. De manera que en los tres regímenes en los que reina la parte concupiscible del alma van apareciendo, en la escena política y en orden creciente, las peores pasiones del hombre: en la oligarquía, los deseos necesarios, en la democracia, los innecesarios que reclaman sus derechos en pie de igualdad junto a los anteriores, y, finalmente, en la tiranía, los

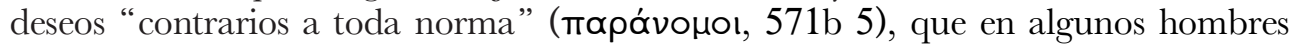
llegan a manifestarse en su verdadera naturaleza bestial y criminal (574a-575b). En la democracia, con "la liberación y el relajamiento de los deseos innecesarios y perjudiciales" (561a 3-4), se establece esa igualdad basada, como hemos visto, en la falta de un criterio adecuado que sepa distinguirlos, pero no se pierde aún todo sentido de la moralidad, porque siguen coexistiendo con los malos los buenos deseos que "no son contrarios a la libertad y a toda norma" (572d 2). Sin embargo, en este combate de unas pasiones contra otras, acaban imponiéndose aquellas que tienen una naturaleza

${ }^{22}$ Cfr. Vallejo Campos 2015, 38 y sgs., 2018, 260-262. 
“terrible, salvaje e inmoral” (åvouov, 572b 5) y no conocen límite alguno que las pueda contener (cf. 571c 7-9).

Sobre la irrupción de estas pasiones en la vida política, Platón insiste en los dos aspectos que hemos venido comentando anteriormente. Por un lado, se trata de pasiones que forman parte de la naturaleza humana, por irracional que nos pueda parecer, y, en consecuencia, "probablemente se producen en todos nosotros" (571b 5-6). Esta naturaleza animal que no reconoce ninguna norma se revela oníricamente (571c 3, 572a 8) y comprende, de hecho, deseos de naturaleza edípica, por mencionarlos con una terminología freudiana que viene muy bien a propósito de estos pasajes ${ }^{23}$. Pero no sería de extrañar que Platón esté pensando también en acciones criminales, como las de Medea, que Eurípides (Med. 1121) califica de la misma manera como actos "contrarios a toda norma", o incluso en prácticas caníbales (cfr. 571d 2-3), que Aristóteles ofrece como ejemplo, entre otros, de una conducta brutal ( ENVII 6, 1148b 19-24). Sin embargo, este es solo un aspecto de la cuestión, porque, por otro lado, está también la contrapartida cognitiva que hace desaparecer estos deseos de nuestra conducta o, por el contrario, los alienta, como sucede en el contexto político que se da cuando se produce el tránsito de una democracia radicalizada a la tiranía. En esta tarea, pueden intervenir, por tanto, por una parte, en un acción positiva destinada a erradicarlos, "las leyes y los deseos mejores junto con la razón"

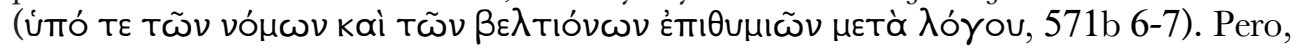
por otra parte, en el contexto político de un conflicto, como el del surgimiento de la tiranía, que desata las peores pasiones del hombre (cfr. 573a-b), hay también opiniones que en tales momentos "son liberadas de la esclavitud" (574d 7) para justificar los peores deseos y pasiones que acaban imponiéndose con el tirano.

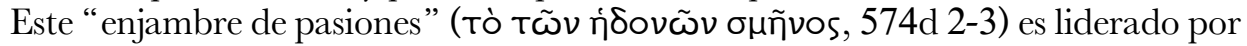
una pasión como el érōs, que tiraniza el alma del nuevo tipo humano llamado a triunfar en la tiranía. Algunos comentaristas se han referido con razón al "misterio de este eros" 24 , ya que no está totalmente claro por qué elige Platón esta pasión para nombrarla capitana del cortejo de deseos incontenibles que se desatan en este régimen. Desde luego, en estas páginas, no se habla de ese otro érōs al que se atribuye una función mediadora entre los dos mundos gracias a su pasión por la belleza y el conocimiento, sino de una pasión que no se detiene ante ningún crimen y que conduce

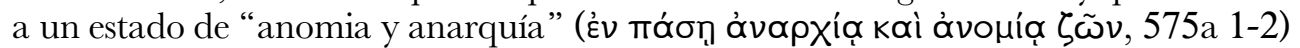
a quien vive dominado por él. Algunos comentaristas han indicado la asociación, que es frecuente en los diálogos, entre la pasión erótica y la ambición de poder, lo cual resulta claro en personajes, como Calicles y Glaucón, o incluso en el mismo Alcibíades ${ }^{25}$. En cualquier caso, del érōs, como pasión concupiscible, en su vertiente

\footnotetext{
${ }^{23}$ Los comentaristas han abundado, como es natural, en las reminiscencias con el análisis freudiano (cfr. KAHN 1987, 83); para las diferencias, véase especialmente SOLINAS 2005, 478 y sgs.

${ }^{24}$ Cfr. PARRY 2007, 396, n. 9.

25 Sobre este punto, cfr. PARRY 2007, 395-396; LudWIG 2007, 224-225; LARRIVÉE 2005, 183-184, y $2015,152-157$.
} 
sexual, por contraposición al "recto amor", se dice en la República que está cercano a "la insolencia y la intemperancia" (403a 2) y que representa "el placer más fuerte y más vivo" (403a 4), por lo que, en definitiva, es el más próximo a "la locura" (403a 6). Justamente, las características de esta pasión sirven a Platón para describir el estado en el que se halla el alma del tirano, cuyos deseos han adquirido una desmesura capaz de destruir todas las normas morales que el hombre democrático no se atrevía a incumplir. Lo mismo que en el estado el tirano se rodea de una pandilla de indeseables, para violar la ley y cometer todo tipo de actos criminales, el personaje que se impone como líder del grupo es un tipo dominado por esta pasión erótica, situada como "caudillo del alma" (573b 1), al frente de otros deseos de parecida naturaleza (573a 4).

El sentido que tenía pasar revista, en la secuencia que hemos visto, a todos los regímenes conocidos, que se desvían del ideal previsto en el estado ideal, queda claro cuando Platón saca las consecuencias que se derivan de todo ello para la teoría de la justicia y la felicidad planteada en la obra. La desgracia y la infelicidad del tirano es la máxima que pueda pensarse respecto al ideal que representa el hombre "perfectamente justo" del estado ideal. De las tres demostraciones que se ofrecen de esta tesis en la República ${ }^{26}$, todas tienen en cuenta precisamente las pasiones como un factor determinante de la justicia y la felicidad. El hombre más justo, pero también el más feliz, es aquel en el que la razón domina a las demás pasiones del alma. Si se consideran las cosas, en primer lugar, desde un punto de vista puramente político, la tiranía, una vez despojada de su "ropaje teatral” (577b), aparece en sus verdaderas miserias, como un régimen en el que un hombre injusto se ha rodeado de los peores para hacerse con el poder. Todo queda en realidad determinado por el factor decisivo de este régimen, que se configura sobre la base de un alma "arrastrada sin cesar por el tábano de sus pasiones" (577e 2). La consecuencia de ello es una vida siempre insatisfecha, asaltada por todo tipo de "temores", "convulsiones" y "dolores", y amenazada por la deslealtad de todos los hombres malvados en los que se ampara su poder (cfr. 578a-580a).

Si se considera la cuestión, en segundo lugar, desde el punto de vista de las partes del alma que prevalecen en cada régimen, hay que comparar los tipos de vida que se configuran sobre esa base: la vida del amante del conocimiento, que se da en la aristocracia, la del amante del honor, en la que se impone la pasión por el triunfo y el reconocimiento, propio de la timocracia, y la del amante del lucro, propia de los demás regímenes (oligarquía, democracia, tiranía), con las pasiones concupiscibles características de la parte apetitiva. También aquí sale triunfante, a juicio de Platón, la vida basada en la razón, porque, de "las tres especies de placer" que están en juego, aquellos que corresponden a la parte racional son considerados superiores a los demás. Lo avala así el filósofo, que tiene experiencia de los tres y dispone del "instrumento" (582d 7) más adecuado para decidir acerca de la mayor o menor excelencia de cada

${ }^{26}$ Cfr. Vallejo Campos 2018, 276-288. 
uno, pues este instrumento no es otro que la inteligencia y la razón (582a-d). La vida mejor y el régimen político que la promueve son juzgados, pues, a partir de las características propias de las pasiones que prevalecen en ellos y los placeres que corresponden a tales formas de vida.

La tercera demostración se centra específicamente en la calidad del placer que es el objeto, como hemos visto, de las pasiones. Platón adelanta en la República una teoría del placer, que expondrá igualmente en el Filebo (31e-32a, 35a ss.), según la cual el placer aparece, después de un proceso de vacío (85b 3, cfr. Phlb. 35a ss.), causado por las necesidades, con la plenitud (585a 3) que se alcanza cuando se suplen las carencias que experimenta el sujeto. En su exposición, Sócrates corrige el punto de vista del sentido común y se refiere a "los llamados placeres" (584c 5), porque la mayoría de ellos, que, para la opinión general, son "los más numerosos e intensos" (584c 5-6), no lo son "en verdad", al constituir simplemente "una liberación del dolor" (584c 1-2). No podemos entrar aquí en la compleja teoría platónica del placer, pero debemos dejar constancia de que una vez más una cuestión como esta, que se examina al hilo de la justicia del estado y la felicidad del individuo, está directamente relacionada con las pasiones. Los verdaderos placeres, que no están contaminados por estos procesos de vacío que se experimentan como dolor, son especialmente aquellos que tienen como objeto procesos en los que interviene el conocimiento $(584 \mathrm{c} 7$ ) y la inteligencia (586a 1): solo quienes tienen experiencia de estos pueden "disfrutar de

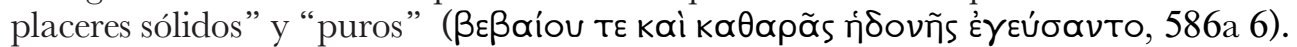
Para alcanzar estos verdaderos placeres es necesaria la razón, pero también la virtud (cfr. 586a 1), ya que, en otro caso, en una vida basada en las pasiones propias de las otras partes del alma, el sujeto, a juicio de Sócrates, se ve abocado a sufrir a causa de la insaciabilidad (586b 2) y "los amores enloquecedores" (586c 2) que hacen desgraciados a los hombres. Si esto es así, cuando el alma se deja conducir por las pasiones de su parte concupiscible, lo mismo ocurre con la parte fogosa, ya que aquí se hallan pasiones como la sed de honores, la ambición de victorias y la cólera (586d), que, dejadas a su propio control, sin el orden que se deriva del "razonamiento y la inteligencia” (586d 1-2), se confunden con la envidia, la violencia y el disgusto, con lo cual se producen los placeres mixtos vinculados al dolor que tanto se alejan del "verdadero placer".

El juicio de Platón respecto a la justicia y la felicidad tanto del estado como del individuo se plantea, por tanto, en términos de la relación que se establezca entre la razón y las pasiones. El grado más alto de placer que pueden alcanzar "las pasiones

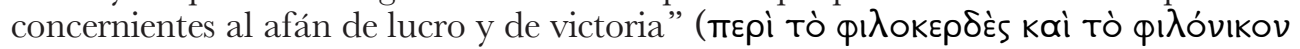

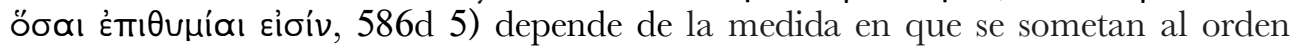

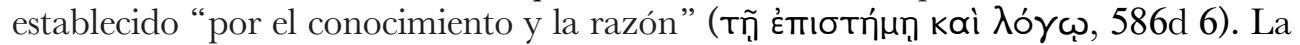
salvación del estado, lo mismo que la del individuo, depende de que prevalezca "el hombre regio" del régimen aristocrático. Dicho en términos de "la imagen del alma" (588b 10) con la que se cierra el libro IX, se trata de que "la bestia polícroma y policéfala" (588c 7-8), en la que residen todas las pasiones concupiscibles que hemos 
examinado, y "el león", que simboliza la parte fogosa, se dejen dominar por "el hombre interior" (589a 7), que representa a la razón. Platón traduce su teoría ética y política a una antropología normativa en la que la salvación del hombre depende de obrar rectamente y esto solo es posible bajo el gobierno de la razón y el sometimiento de su naturaleza pasional. El hombre interior, "provisto de inteligencia” (591c 1), está llamado a ejercer su gobierno sobre la bestia multiforme y el león colérico que habitan en su interior.

En las Leyes hay variaciones enormes del planteamiento político de Platón, en las que ya no podemos entrar. Sin embargo, podríamos decir que en esta obra más que en ninguna otra se acrecienta su convicción de la importancia de las pasiones en la vida humana y de la necesidad de encauzarlas con el ordenamiento legislativo del estado. El hombre, se nos dirá allí (644d), es una marioneta de los dioses, arrastrada por dos cuerdas "duras y férreas", que son el placer y el dolor, pero son "estas pasiones

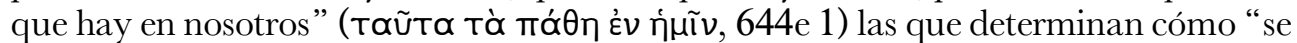
define en nuestras vidas la virtud y el vicio" (644e 4). Junto a ellas hay también una cuerda más fina y débil, que representa "la dirección áurea y sagrada del cálculo racional" (645a 1). Perdida la esperanza de encontrar al guardián perfecto cuya inteligencia esté por encima del ordenamiento legal, el remedio para el anciano Platón consiste en llamar razón a lo dispuesto por la ley. En cualquier caso, ya se trate de un hombre solo, de una oligarquía o de una democracia, la salvación no será posible si

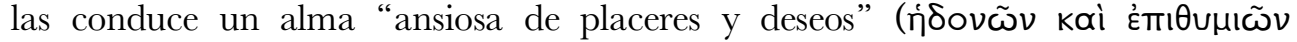

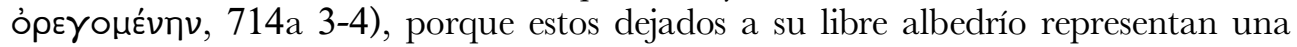
desgracia y una enfermedad "infinita e insaciable" (714a 5) que conduce a la destrucción de la comunidad.

\section{Bibliografía}

Barker, E. (1961), Greek Political Theory, Plato and His Predecessors, Londres-New York, $\left(1918^{1}\right)$.

Bertelli, L. (2005), «Platone contro la democrazia e l’oligarchia», en Vegetti (2005), 295-396. Calonge Ruiz, J. (1990), «Introducción general», en Tucídides, Historia de la Guerra del Peloponeso, trad. y notas de J.J. Torres Esbarranch, Madrid, 8-110.

Campese, S. (2005), «L'oikos e la decadenza della città», en Vegetti (2005), 189-261.

Dodds, E.R. (1990), Plato, Gorgias, A revised text with introduction and commentary, Oxford (19591).

Ferrari, G.R.F. (2007) (ed.), The Cambridge Companion to Plato's Republic, Cambridge.

Gastaldi, S. (2003), «L'allegoria della nave», en Vegetti (2003), 187-216.

Jaeger, W. (1971), Paideia: Ios Ideales de la Cultura Griega, México (1933-19451).

Kahn, C. (1987), «Plato’s Theory of Desire», Review of Metaphysics XLI, 77-103.

Laclau, E. (1994), La razón populista, Madrid, 2016.

Larrivée, A. (2005), «Malaise dans la cité. Eros et tyrannie au livre IX de la République», en Dixsaut, M. (ed.), Études sur la Republique de Platon, I, De la justice, París, 169-197. 
Larrivée, A. (2013), «Alcibiades as the Model of the Tyrant in Book IX of the Republic», en Notomi, N. - Brisson, L. (eds.), Dialogues on Plato's Politeia (Republic), Sankt Augustin, 152-157.

Ludwig, P.W. (2007), «Eros in the Republio», en Ferrari (2007), 202-231.

Parry, R. (2007), «The Unhappy Tyrant and the Craft of Inner Rule», en Ferrari (2007), 386-414.

Romilly, J. de (1975), Magic and Rhetoric in Ancient Greece, Harvard.

Schofield, M. (2006), Plato, Political Philosophy, Oxford.

Segal, C.P. (1962), «Gorgias and the Psychology of the Logos», Harvard Studies in Classical Philology 66, 99-155.

Solinas, M. (2005), «Desideri: Fenomenologia degenerativa e strategie de controllo», en Vegetti (2005), 471-498.

Vallejo Campos, A. (1993), «Conflicto en Torno al Lógos. El concepto de téchnē y la crítica filosófica de la retórica», Er, Revista de Filosofía XV, 9-42.

Vallejo Campos, A. (2002), «Razón, seducción y engaño en la retórica antigua: la crítica platónica», Bitarte 27, 23-43.

Vallejo Campos, A. (2015), «Deseos y valores. El intelectualismo socrático y la tripartición del alma en la República», Revista de Filosofía XL 2, 23-43.

Vallejo Campos, A. (2016), «Socrates as a Physician of the Soul», en Cornelli, G. (ed.), Plato's styles and characters, Berlin, 227-239.

Vallejo Campos, A. (2018), Adonde nos lleve el logos. Para leer la República de Platón, Madrid.

Vegetti, M. (1995), La medicina in Platone, Venezia.

Vegetti, M. (1998), «Medicina» en Vegetti (1998b), 427-444.

Vegetti, M. (ed.) (1998a), Platone. La Repubblica, I, Libro I, Napoli.

Vegetti, M. (1998b), Platone. La Repubblica, II, Libro II y III.

Vegetti, M. (1998c), Platone. La Repubblica, III, Libro IV.

Vegetti, M. (2000), Platone. La Repubblica, IV, Libro V.

Vegetti, M. (2003), Platone. La Repubblica, V, Libros VI y VII.

Vegetti, M. (2005), Platone. La Repubblica, VI, Libros VIII-IX.

Vegetti, M. (2007), Platone. La Repubblica, VII, Libro X.

Villacañas Berlanga, J.L. (2015), Populismo, Madrid. 